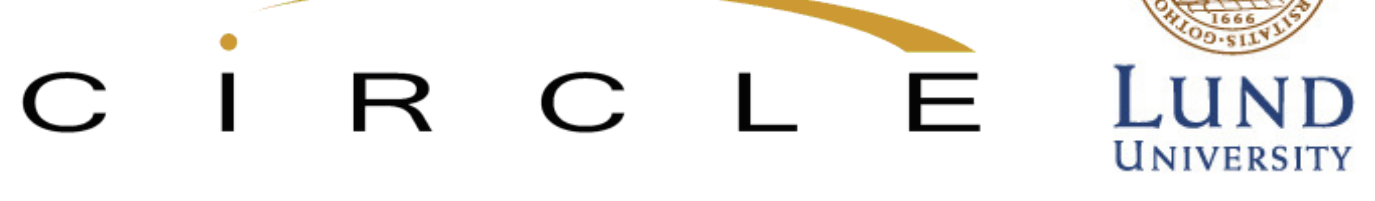

\title{
Unrelated knowledge combinations: Unexplored potential for regional industrial path development
}

\author{
Markus Grillitsch (markus.grillitsch@keg.lu.se) \\ Department of Human Geography \& CIRCLE, Lund University, Sweden \\ Bjørn Asheim (bjorn.t.asheim@uis.no) \\ University of Stavanger, Norway and CIRCLE, Lund University, Sweden \\ Michaela Trippl (michaela.trippl@univie.ac.at) \\ University of Vienna, Austria \\ Papers in Innovation Studies \\ Paper no. 2017/10
}

This is a pre-print version of a paper that has been submitted for publication to a journal.

This version: July 2017

Centre for Innovation, Research and Competence in the Learning Economy (CIRCLE)

Lund University

P.O. Box 117, Sölvegatan 16, S-221 00 Lund, SWEDEN

http://www.circle.lu.se/publications 


\title{
Unrelated knowledge combinations: Unexplored potential for regional industrial path development
}

\author{
Markus Grillitsch, Bjørn Asheim, Michaela Trippl
}

\begin{abstract}
The paper engages in a critical discussion of the related variety - regional branching argument and foregrounds a more differentiated perspective on regional industrial path development. It contributes by i) sharpening the definition of key concepts, namely specialisation and diversity, related and unrelated variety, ii) discussing their relevance in local and non-local spaces, iii) scrutinizing related variety as source for regional branching, and iv) developing a conceptual framework capturing the opportunity space for regional structural change that unveils the relevance of path upgrading, path importation, path branching, path diversification, and new path creation as different forms of new path development.
\end{abstract}

Keywords: industrial path development; economic diversification; regional structural change; specialisation and diversity; related and unrelated variety; knowledge base combinations

JEL: B52; O10; R10; R58

Disclaimer: CIRCLE does not take any responsibility for opinions and views expressed by the authors in this paper. 


\title{
Unrelated knowledge combinations: Unexplored potential for regional industrial path development
}

\author{
Markus Grillitsch, Lund University, Bjørn Asheim, University of Stavanger and Lund \\ University, and Michaela Trippl, University of Vienna.
}

\begin{abstract}
The paper engages in a critical discussion of the related variety - regional branching argument and foregrounds a more differentiated perspective on regional industrial path development. It contributes by i) sharpening the definition of key concepts, namely specialisation and diversity, related and unrelated variety, ii) discussing their relevance in local and non-local spaces, iii) scrutinizing related variety as source for regional branching, and iv) developing a conceptual framework capturing the opportunity space for regional structural change that unveils the relevance of path upgrading, path importation, path branching, path diversification, and new path creation as different forms of new path development.
\end{abstract}

Keywords: industrial path development, economic diversification, regional structural change, specialisation and diversity, related and unrelated variety, knowledge base combinations

JEL Codes: B52; O10; R10; R58 


\section{Introduction}

A growing community of economic geographers and regional scientists has invoked the notions of related variety and regional branching to analyse regional variations in growth and structural change. Introduced and further developed by Ron Boschma, Koen Frenken and their colleagues in Utrecht (Frenken and Boschma 2007; Frenken et al. 2007), these concepts have become powerful elements in current accounts of regional economic development and diversification. Related variety is presented as a new category that differs from and complements the long-established concepts of specialisation and diversity. Related variety is seen as a key source of regional branching, where new industries grow out of existing ones through endogenous processes taking place within the region, that is, in local space. Notwithstanding their growing popularity, there has been relatively few in-depth reviews of the key assumptions and main arguments of the two notions.

The overall aim of this paper is to engage in a critical discussion of the concepts of related variety and regional branching. We identify a set of shortcomings that surround these notions and develop a more comprehensive conceptual framework for regional structural change. Our contribution to the debate is fourfold. First, we argue that the distinction between specialisation (localisation economies) and related variety may be less clear cut than the protagonists of the latter want us to believe, as this view rests on a (too) narrow understanding of the former. Second, we scrutinise the mechanism through which related variety contributes to regional branching. Third, we claim that regional branching constitutes only one form of new path development among others. The paper provides a more differentiated understanding of regional structural change by discussing other forms of path development, that is, path upgrading, path importation, path branching, path diversification, as well as new path creation. Finally, we take up a critical stance on the exclusive focus on the local space that characterizes the majority of work on regional diversification. We contend that assets and processes on which regional structural change is based can be found both in local and global spaces.

The paper proceeds with a discussion of related variety and regional branching (section 2), which is then contrasted with the concept of specialisation (section 3). Section 4 elaborates on the virtues of diversity beyond the portfolio theory. Section 5 focusses on sharpening the definitions and boundaries of these concepts. We continue with introducing the local and nonlocal dimension in section 6 and with discussing a typology of industrial path development in 
section 7. This leads to our proposed conceptual framework in section 8. Section 9 concludes the paper.

\section{Related variety and regional branching}

The related variety argument has been very influential in explaining regional growth (Content and Frenken 2016) as well as the diversification of regional economies into areas of economic activities related to the ones developed in the past (Frenken and Boschma 2007). The concept was first introduced by Frenken, Van Oort and Verburg (2007) in an attempt to understand "which precise composition of sectors in a regional economy creates most spillovers" (ibid, p. 687). The original idea departed from a discussion about the different types of agglomeration externalities. Localisation economies or MAR externalities are associated in this literature with external economies accruing within the same sector spurring mainly incremental innovations, due to increase in labour productivity but not necessarily employment. Jacobs externalities refer to external economies arising to local firms due to a variety of sectors. The main idea introduced in Frenken et al. (2007) is that Jacobs externalities are of two kinds: i) variety reducing risk in the event of industry specific shocks in line with the portfolio theory, and ii) variety in terms of knowledge spillovers between different sectors. While reduction of risk requires that sectors are unrelated, the authors expect "knowledge spillovers within the region to occur primarily among related sectors, and only to a limited extent among unrelated sectors" (ibid p. 688). Related variety is thought to stimulate product innovation and niche creation and can for instance be promoted by spin-offs, thereby contributing to regional employment growth, evidence of which was found in empirical studies (Saviotti and Frenken 2008; Boschma et al. 2012).

While Frenken et al. (2007) do not specify explicitly in what sense sectors are to be related, the interpretation of the concept has converged around the idea that "inter-industry spillovers occur mainly between sectors that draw on similar knowledge: knowledge originating from one sector is most relevant to, and can most effectively be absorbed by, another sector that is related in the sense that firms draw on similar knowledge (about technology, markets, etc.)." (Content and Frenken 2016, p. 1) This resonates with the idea that a certain degree of cognitive proximity is required for knowledge exchange to occur (Boschma 2005). 
The concept of related variety is a key element in the evolutionary concept of regional branching, which, as its main contribution, introduces firm-level dynamics for explaining regional economic growth (Frenken and Boschma 2007). Regional growth essentially results from firm-level diversification into related economic activities: "[F]irms typically diversify into products that are technologically related to its current products" (ibid, p. 637). Firm diversification gives raise to regional diversification, which in turn stimulates firm and regional growth. Larger firm sizes produce economies of scale in $R \& D$ and larger urban sizes create urbanization externalities, both of which are supposed to stimulate innovation. As regards economies of scale in $R \& D$ and urbanisation externalities resulting from growth, the authors argue as follows: "the more product varieties already present in a firm or city, the higher the probability new product varieties can be generated through recombination of old routines. This feedback relationship is non-linear in that the potential for new ideas rises more than proportional with the stock of existing ideas. Thus, even though the process of growth increases the potential product variety in firms and in cities, firms and cities are expected to be specialized in varieties that fall under a small set of product groups." (ibid, p. 642)

The concepts of related variety and regional branching underpin an evolutionary theory of regional industrial change, neglecting, however, the potential of unrelated knowledge in innovation processes. In order to foreshadow our conceptual framework presented further below, the combination of ex-ante unrelated knowledge with existing competencies in the firm or region is a feasible and important source to stimulate innovation and new path development. Furthermore, despite notable exceptions (e.g. Boschma and Iammarino 2009; Boschma et al. 2016) most studies focus on relatedness of sectors within the region thus ignoring related and unrelated sources for innovation on a non-local scale (Trippl et al. 2017).

\section{Specialisation}

The literature in economic geography on specialisation has various roots going back to Marshall (1920) but is captured more recently in notions such as industrial districts (e.g. Pyke et al. 1990; Asheim 2000) and clusters (e.g. Pouder and St. John 1996; Porter 1998; Asheim et al. 2006). These bodies of work interpret specialisation and localisation economies notably broader as compared to the literature on related variety. Accordingly, specialisation is not about economies that occur due to the spatial clustering of activities in "one sector" but about interdependencies between sectors that are functionally related. In early work on industrial 
districts, local production systems and even clusters, the emphasis was still on functional interdependencies in production (i.e. input - output linkages), which has soon shifted to focus on knowledge interdependencies, learning and innovation.

The following definition of clusters is a typical example: "Clusters are geographic concentrations of interconnected companies and institutions in a particular field. Clusters encompass an array of linked industries and other entities important to competition. [...] Clusters also often extend downstream to channels and customers and laterally to manufacturers of complementary products and to companies in industries related by skills, technologies, or common inputs." (Porter 1998: 78) What becomes evident from this definition is that specialisation is not understood as concentration within "one sector" but comes much closer to what was above defined as "related variety". Competitive advantage rests to a large extent on local endowments of knowledge and linkages between related firms (that can span a variety of sectors), which spurs learning and innovation. Kemeny and Storper (2015) argue in a similar manner, suggesting that related economic activities should be considered as regional specialisation.

Specialisation is theoretically not delineated by a single sector but by the interdependencies arising from complementary economic activities. These interdependencies extend narrow sector classification and relate to broader fields of economic activities. Interdependencies arise through the interplay of actors in production processes as well as in learning and innovation processes. Learning and innovation processes are typically interactive involving a large variety of actors such as customers, suppliers, competitors, as well as other firms and supporting organisations (Lundvall 1988). The notion of specialisation relates to the division of labour in a production and innovation system that allows for the accumulation of very specific competences and resources as well as the routines and institutions that facilitate recombination.

Storper et al. (2016: 1629) make another important claim, namely that specialisation and diversity "can only be understood over time, in light of broad tendencies of the economy-wide phases of development (e.g., old economy to new economy), and over space in terms of the economy-wide division of labour and how it evolves over the life of the economy-wide dynamic." The argument builds on the industry life-cycle theory and stipulates that dynamic, innovation-based sectors like ICT and life-sciences are highly clustered due to a number of 
factors such as high rates of change in technologies and markets, thus high uncertainties and high stickiness of knowledge, and the need of conventions in order to overcome these uncertainties and facilitate knowledge sharing. Mature industries in contrast have moved out of previous centres to cheaper locations.

In essence, specialisation foregrounds the effects on learning and innovation due to the collocation of interrelated activities in a particular field. Such a field can relate to a certain technology (e.g. semiconductors) or an industry (e.g. automotive) but is not delineated by the technology or industry. Rather it is the core of traded and untraded interdependencies (Storper 1995) that typically cross sectoral boundaries. However, specialisation (like the related variety concept) ignores the potential contribution of unrelated knowledge as well as extra-regional inputs to learning and innovation.

\section{Diversity: the virtue of unrelated variety beyond the portfolio theory}

The related variety argument limits the role of Jacob's diversity (unrelated variety) to portfolio effects (Frenken et al. 2007) while some proponents of the specialisation concept more generally reject the idea that the existence of a diverse set of unrelated economic activities may stimulate learning and innovation (Kemeny and Storper 2015; Storper et al. 2016). In contrast, we argue that unrelated variety is an important source for learning and innovation. Furthermore, to interpret Jacob's diversity to cover only portfolio effects is too narrow if reference is made to the impact of diversity/unrelated variety on creativity and innovation (i.e. knowledge spillovers) (cf. Florida et al. 2017). The portfolio effect alone cannot substantiate the basic argument of the dynamic role of cities.

In the literature on both specialisation and related variety the argument departs from the assumption that knowledge, which is fundamentally different in nature, is very difficult to combine. Specialisation and related variety capture industries with knowledge that is similar enough to allow for interactive learning and knowledge transfer and thus innovation. In contrast, unrelated variety comprises sectors with dissimilar knowledge anchored in different institutional domains, thereby making them arguably ill-suited for cross-sector learning and knowledge exchange. 
In contrast to the work on specialisation and related variety, evidence suggests that unrelated knowledge is combined in innovation processes through different mechanisms such as collaborations, recruitment, strategic alliances, or acquisitions. In this regard, the knowledge base concept provides the theoretical background to numerous empirical studies. It differentiates between analytical, synthetic, and analytical knowledge. Analytical knowledge is generated through scientific methods and characterized by its universal, highly abstract and to a large extent codified nature. Collaborations with universities and research institutes are common. Synthetic knowledge is gained through the application or combination of existing knowledge, typically in interactive learning processes with customers or suppliers, and has a strong tacit and context specific dimension. Symbolic knowledge rests on creative processes in project teams and is essential for creating meaning, desire, and aesthetic qualities. Symbolic knowledge is intangible and highly context specific. The three knowledge bases differ substantially in many respects; still their combination is feasible and conducive for innovation processes (Grillitsch et al. 2016).

Strambach and Klement (2013), for instance, analyse the innovation biography of an automated content management tool that allows for standard visualisation procedures and thus the management of large-scale projects. Symbolic knowledge about interpreting cars in different contexts globally was combined with synthetic knowledge about visualisation technologies and content management technologies. The knowledge was unrelated at the time when it was brought together and the combination involved different mechanisms such as collaborations and recruitment. Another example is the food industry, which can be characterised as traditional industry resting on synthetic knowledge. The introduction of science-based, analytical knowledge from biotechnology, however, has led to the generation of high-value added functional foods with particular health benefits (Zukauskaite and Moodysson 2016). A similar example would be traditional textile and shoes industries moving into technical textile and shoes by adding nanotechnology (analytical knowledge base) to the traditional (synthetic) knowledge base of the industry. These examples illustrate how dissimilar knowledge is combined (i.e. it is not related variety) from sectors that are characterised by a low degree of interdependencies (i.e. it is not specialisation). However, through the innovation process, the sectors become related and may spark a new specialisation, e.g. in advanced IT solutions or in functional foods. 
Therefore, the combination of unrelated knowledge can lead to the emergence of related industries. At the heart of this argument is the experimental and evolutionary character of new path development. The starting point is the search for competitiveness and high-value creating activities driven by entrepreneurs. In order to become more competitive, entrepreneurs experiment in innovation processes where the combination of unrelated but complementary knowledge offers a high potential for introducing novelty. Successful experiments signal viable business opportunities to the market. These newly discovered opportunities may trigger new specialisations through spin-offs, imitation and allocation of resources to the new niches. Formerly unrelated knowledge and industries become related because of increasing interactions between the initially distinct fields in the form of for example collaborations, labour mobility, strategic alliances and mergers as well as business decisions to invest in the newly discovered market niches for new products.

\section{Disentangling specialisation and diversity, related and unrelated variety}

The above review of core contributions on specialisation, related and unrelated variety reveals some overlaps and misunderstandings. Should specialisation be delineated by a specific sector (as related variety scholars do) or more broadly by the interdependencies that radiate from a given focal field? Take the tourism industry as an example. How can specialisation in the tourism sector be understood? The first issue relates to an adequate delineation of the sector. The tourism sector includes a variety of services such as accommodation, food and beverage but also transport, and entertainment and recreation. Furthermore, as regards learning and innovation, the interdependencies are often not between the aforementioned industries but with business services such as ICT firms, advertising and new media, purchasing cooperatives, or training and education institutes. Hence, the relevant interdependencies are anchored in a variety of industries and sectors that co-develop with an innovation-based tourism industry. In contrast, tourism as a one-sector specialisation can be conceived in developing countries where international hotel chains build resorts at attractive locations and use local cheap labour whereas the relevant knowledge and competences are developed in other locations. In the latter case, however, tourism is embedded in a resource-based and not knowledge and innovation-based economy, the resource being immobile natural or cultural attractions. 
Similar thought experiments can be constructed for virtually every sector. In the context of a knowledge and innovation-based economy, it is therefore not useful to conceptualise specialisation by a single sector but by the interdependencies in terms of learning and innovations that support a particular field of economic activity. This, however, absorbs some of the turf currently occupied by the related variety concept. Especially the measurements of related variety based on sector classifications, labour flows, or co-occurrence show a heavy overlap with what is defined here as specialisation.

The consequent question is whether related variety can be conceived in a way that creates an exclusive category not overlapping with the idea of specialisation. This is the case if related variety is defined as existing between two sectors that exhibit similarities in a specific type of knowledge but have (to a large extent) developed independently from each other. The second conditions implies that historically there are no (or very limited) interdependencies between the two sectors that support learning and innovation and thus ensures a neat delimitation from specialisation.

For example, the Austrian ski manufacturer Fischer had developed strong competences in compound materials and - based on this knowledge - diversified into the aviation industry, which also uses compound materials in the construction of airplanes. This led to the establishment of FACC, a 100\% daughter company of Fischer in 1989, and a steady growth of the firm to become one of the leading compound materials component suppliers in the aviation industry. This constitutes related variety and not specialisation because knowledge similarities in the knowledge base allowed Fischer to diversify into the aviation industry and because there were no interdependencies in terms of learning and innovation between the two sectors before this connection was made. Note that this also illustrates branching based on firm diversification.

Diversity then captures effects of related variety as defined above and of unrelated variety. Unrelated variety contributes to new path development due to the learning and innovation potential arising from the combination of dissimilar/unrelated knowledge. In this regard, we do not agree with Storper et al. (2016, p. 1629) who argue that "in contemporary high technology, the fortunes of lawyers, investment bankers, venture capitalists and programmers are all intertwined if they are related through input-output linkages and dependent on the same source of demand, the same innovative dynamics, the same regional price system. They 
do not make for a diversified regional economy, because they are part of an interdependent ecosystem. This is not 'related diversity,' but specialization."

We argue that this very comprehensive understanding of localisation economies goes too far. Lawyers, investment bankers and other knowledge intensive business services concentrate in cities and can in principle serve a wide range of sectors, thus they are part of urbanisation economies. For instance, legal advice or financial services for the merger or acquisition of companies is a generic competence not per se limited to a specific sector. Such services illustrate that specialised sectors in city regions can at the same time benefit from localisation and urbanisation economies. Furthermore, knowledge intensive business services often serve local, national and international clients, thus, underlining the role of cities in nonagglomerated systems of value creation as discussed in the following section.

\section{Concrete geographic and abstract economic space}

As a result of globalisation regions cannot remain exclusively based on local resources but are more successful when they are functionally linked across wider spaces. This implies that firms can exploit external economies as a result of both agglomerated and non-agglomerated activities, benefiting from being co-located in space as well as being integrated in non-local networks. However, despite some noteworthy exceptions, the literature on related variety, specialization and urbanisation largely underplayed the potential contributions of non-local knowledge and resources when explaining why certain regions perform better than others.

Perroux (1970) referred to the exploitation of non-agglomerated external economies of firms' networks not co-located in space as 'growth poles' in 'abstract economic space', distinguishing them from agglomerated external economies arising from co-locations of firms in 'concrete geographic space'. Interestingly, Porter (1990: 149) also pointed to nonagglomerated clusters, arguing that "a nation's successful industries are usually linked through vertical (buyer/supplier) or horizontal (common customers, technology etc.) relationships". However, in his later work clusters were defined as "geographic concentrations of interconnected companies and institutions in a particular field" (Porter, 1998:78). This has led to a strong focus on local and an under-appreciation of non-local drivers of clusters. 
Concrete geographic space and abstract economic space are two distinct but a priori equally relevant categories. As regards specialization, Storper (1995, p. 192) argues that untraded interdependencies "generate region-specific material and non-material assets in production". This view would need to be extended to capture that interdependencies (in particular as regards learning and innovation) can accrue through interactions between actors locally in the form of localisation economies but also globally. There is no lack of evidence for the latter as research on global production and innovation networks confirms (e.g. Henderson et al. 2002; Chaminade and Vang 2008; Cooke 2012).

Equally, related variety can potentially contribute to learning and innovation in concrete geographic spaces, through collocation, as well as in abstract economic spaces, through extraregional linkages. The related variety argument was developed on the back of theories on agglomeration economies and knowledge spillovers, i.e. emphasising the concrete geographic space. However, there are also some contributions that extend the related variety to extraregional trade linkages (Boschma and Iammarino 2009) and neighbouring regions (Boschma et al. 2016).

The logic of the related variety arguments echoes in the product space concept (Hidalgo et al. 2007), which is theorised and empirically captured as an abstract economic space. According to the product space concept the likelihood that countries diversify into a new product depends on the proximity in terms of the required technology, capital, institutions, and skills to the products the country already produces. Regions or countries can evolve within this abstract economic space depending on their current industry structure.

Unrelated variety in a concrete geographic space has been captured by the concept of urbanisation economies. While geographic proximity facilitates the search for unrelated knowledge, it is conceivable that firms seek unrelated knowledge outside the region; in abstract economic space, which connects to the global innovation network concept (Cooke 2012; Parrilli et al. 2013). Accordingly, the most advanced knowledge, research capabilities, and innovation capacities are concentrated in few locations worldwide that are interconnected through collaborations and flows of researchers (Trippl 2013). 


\section{New path development}

Recent literature in economic geography zooms in on the nature of new industrial path development (Martin and Sunley 2006). From rather broad categories of new path development, more fine-grained typologies have been developed recently (Grillitsch and Trippl 2016; Isaksen et al. 2016). Building on this work, Table 1 summarises the main forms and mechanisms of regional industrial path development.

Table 1: Types and mechanisms of regional industrial path development

\section{Forms of path development Mechanisms}

Path extension

Continuation of an existing industrial path based on incremental innovation in existing industries along wellestablished technological trajectories

Path upgrading

I - Climbing GPN

II - Renewal

III - Niche development

Path importation

Path branching

Path diversification

Path creation
Major change of a regional industrial path related to enhancement of position within global production networks; moving up the value chain based on upgrading of skills and production capabilities

Major change of an industrial path into a new direction based on new technologies or organisational innovations, or new business models

Development of niches through the integration of symbolic knowledge

Setting up of an established industry that is new to the region (e.g. through non-local firms) and unrelated with exiting industries in the region.

Diversification into a new related industry for the region building on competencies and knowledge of existing industries

Diversification into a new industry based on unrelated knowledge combinations

Emergence and growth of entirely new industries based on radically new technologies and scientific discoveries or as an outcome of search processes for new business models, user-driven innovation and social innovation

Source: own elaboration, inspired by (Grillitsch and Trippl 2016; Isaksen et al. 2016) 
Path extension is the outcome of incremental innovations in firms. It represents continuity of industrial structures and is first and foremost based on the use of existing knowledge. Limited generation of or access to new complementary knowledge constrain the innovation potential of regional industries and may result in stagnation and decline (Isaksen and Trippl 2016).

Path upgrading points to major intra-path changes, that is, changes of an existing regional industrial path into a new direction. One can distinguish between three subcategories of upgrading. First, such processes could be triggered by the infusion of new technologies or major organizational changes (renewal). Second, upgrading can be related to an improvement of the position of the regional industry within global production networks (climbing GPNs). This may take place through processes of value enhancement based on the development of more advanced functions, more specialized skills, etc. (Coe et al. 2004; MacKinnon 2012). Third, upgrading might also be related to the development of niches in mature industries, driven by the integration of symbolic knowledge (e.g. in the food and beverage industry as well as in tourism) (niche development).

Path importation refers to the setting up of established industries that are new to the region and not related to other industries present in the region. Such processes could be triggered by the arrival of non-local companies, inflow of skilled individuals with competences not available in the region or innovation partnerships with distant sources. Inward investment by non-local companies is often seen as a key route for path importation, particularly if these firms feature high value-added functions and embed themselves in the regional economy by creating links to regional actors.

Path branching implies that new regional industrial paths emerge building on the capabilities in existing industries. Such processes may have several sources. An important mechanism is the diversification of incumbent firms into related fields and industries based on the redeployment of existing assets. Branching can also occur through the foundation of new firms based on competencies in existing industries. Spinoffs from incumbents have been found to play a key role for path branching (Klepper 2007).

Path diversification is, like path branching, explained as a micro-level process, where firms move into new industries by combining their existing knowledge base with new, unrelated knowledge. For example, traditionally textile production is based on oil or wool as raw 
materials. Now new fabrics resembling silk of 'Hermes quality' and cashmere can be fabricated from the waste pulp of orange juice and from milk protein respectively. Such fabrics have properties of wearables (technical textile) of being 100 percent breathable and body moisturizing as well as not requiring frequent laundering, thus reducing the environmental impact. In addition, the fabrics have aesthetic qualities that make them useable in the fashion industry. The Italian luxury house Salvatore Ferragane in collaboration with Orange Fiber (the peel-recycling company) uses a silk-mix manufactured in large part from the recycled fruit waste in a collection of pretty print scarves and dresses (Ellison 2017). This merging of high-tech, traditional textile and fashion represents path diversification based on unrelated combinations of analytical, synthetic and symbolic knowledge bases, manufacturing products with high-value added potentials while at the same time being sustainable.

Path creation into new industries represents the most radical form of change. It is brought about by the emergence and growth of industries based on new technological and organizational knowledge. There is a growing consensus that chance or historical accidents should not be overemphasized as causes for new path creation, because they often emerge 'in the context of existing structures and paths of technology, industry and institutional arrangements' (Martin and Simmie 2008:186). More specifically, path creation in new industries is often based on the existence of assets, resources or competencies rooted in the area, such as an excellent scientific base (Martin and Sunley 2006). The emergence of new high-tech and knowledge-intensive industries often hinges on the establishment of new companies and spin-offs (Bathelt et al. 2010). Also existing endogenous firms and universities (Tanner 2014) as well as the inflow of individuals, entrepreneurs and firms from outside (Neffke et al. 2014; Trippl et al. 2017) can play a role in 'seeding' new paths.

Having disentangled various forms of path development, in a next step we discuss how these forms are underpinned by specialisation, related variety and unrelated variety found both at the local and global space.

\section{Conceptual Framework}

The conceptual framework (Table 2) captures the opportunity space for regional industrial path development in two dimensions: Space (concrete geographic and abstract economic space) and industry structure (specialisation and diversity, the later divided in related and 
unrelated variety). Concrete geographic space refers to the local arena for knowledge exchange and learning. Abstract economic space refers more generally to the knowledge and technology that is used and developed in the realm of specific industries, and which per se is not confined within a specific territory.

Table 2: Opportunity space for regional industrial path development

\begin{tabular}{|l|l|l|}
\hline & $\begin{array}{c}\text { Concrete geographic space } \\
\text { (Local space) }\end{array}$ & $\begin{array}{c}\text { Abstract economic space } \\
\text { (Non-local space) }\end{array}$ \\
\hline Specialisation & $\Rightarrow$ Extension & $\begin{array}{l}\Rightarrow \text { Extension } \\
\Rightarrow \text { Climbing GVC }\end{array}$ \\
\hline Related variety & $\Rightarrow$ Shifts between paths & $\Rightarrow$ Path branching \\
\hline Unrelated variety & $\Rightarrow$ Niche development & $\Rightarrow$ Renewal \\
$\Rightarrow$ Path diversification & $\Rightarrow$ Renewal \\
& $\Rightarrow$ Path creation & $\begin{array}{l}\Rightarrow \text { Path importation } \\
\Rightarrow \text { Path diversification }\end{array}$ \\
\hline
\end{tabular}

Specialisation as a source of learning rests on knowledge linkages between actors in a specific field. Such knowledge linkages promote learning within the framework of a given industrial path, hence, promotes path extension. The abstract space of an industry is defined by industryspecific institutions and technologies, which create a common frame for interactions regardless the location of the actors. Specialisation in concrete geographic space can be associated with dynamic regions such as Silicon Valley (Saxenian 1994) as well as with declining regions such as old industrial regions (Hassink 2010) depending on the character of the specialisation (Storper et al. 2016).

Specialisation can also be a source for path upgrading in the form of climbing the hierarchy in global value chains. One example is the upgrading of the Chinese automotive industry (Nam and $\mathrm{Li}$ 2012). Foreign direct investments were essential to develop production and project execution capabilities in the automotive sector. Knowledge transfer and learning was promoted through import substitution schemes as well as the requirement for foreign companies to establish joint ventures with local firms to access the Chinese markets. Further path upgrading to the top of the hierarchy, which required the capability to innovate and develop new cars, occurred by state supported outward foreign direct investment activities. 
Chinese firms acquired car producers (e.g. Geely took over Volvo) and other knowledge providers (e.g. SAIC acquired Ricardo PLC, an English automotive consultancy) in order to access the required knowledge.

Related variety is a source for path branching. Earlier in this paper, we illustrated path branching by the example of the ski manufacturer Fischer diversifying into the aviation industry. However, if in the respective region both the ski and aviation industry had already existed, the act of Fischer to diversify would not have caused branching into a new regional industrial path. Therefore, path branching based on related variety is linked to the abstract economic space where one industry branches into another one that i) requires similar competencies and that ii) does not yet exist in the region. Furthermore, the literature often ignores that path branching does not necessarily need to be an endogenous process. If a region has developed a strong competence base and thick labour market in a technology that could also be of benefit for another industry (not yet present in the region), path branching can occur because firms from related industries decide to locate or open new branches in the respective region.

This leads us to another important clarification: Related variety in concrete geographic space allows for a better allocation of resources to economic activities that generate higher value. Let's take again the example of the ski and aviation industry and presume that both industries exist in a region. The industries are related because competencies in compound materials are relevant for both. Let's further assume that the ski industry declines while the aviation industry grows. The presence of the aviation industry would then make it relatively easy for a firm in the ski industry with relevant knowledge and technology to re-use its competencies and diversify into the growing aviation industry. In consequence, this means that firms in regions with many related industries will be better able to shift from declining to more dynamic industries, therefore grow more, which at the aggregate level leads to higher regional economic growth rates. In fact empirical studies provide support for the relationship between related variety and regional economic growth (Content and Frenken 2016). Thus, related variety in a concrete geographic space is a source for shifting competencies and resources from one industrial path to another.

Unrelated variety opens up a number of additional opportunities for regional industrial path development. Path upgrading can occur through path renewal and niche development. An 
example is the use of electric or hydrogen engines in cars. These technologies, which are introduced to the automotive industry, may in the long-term even replace the current core technology based on combustion engines. Path diversification differs from path upgrading insofar as it captures firm diversification into hitherto unrelated industries, which was exemplified by the capacity of producing fabrics resembling silk and cashmere with aesthetic qualities that make them usable in the fashion industry from fruit waste and milk protein. In principle, unrelated variety can be a source for learning and innovation within concrete geographic and abstract economic space. However, due to the relative cognitive distance associated with unrelated variety, co-location in the same concrete geographic space is an important facilitator for these forms of industrial path development (Boschma 2005).

Moreover, unrelated variety offers potential for the emergence of industries new to the world (path creation) or industries new to the region (path importation). We argue that concrete geographic space is essential for new path creation because at the point of industry emergence, key knowledge is not codified and standards are not established. Hence, the learning dynamics rest on the interactions of individuals who hold the key knowledge, and which makes face-to-face contacts and direct social ties essential. This resonates well with the story of Storper et al. (2015) about San Francisco's economic actors who invented new practices in IT and biotech that sparked the emergence of new industries. In addition, new industries are typically reliant on a variety of knowledge intensive business services (e.g. high-level financial, legal, and marketing services) as well as the entrepreneurial competencies to develop new business models. Missing one of these elements in the region creates major obstacles in kick-starting a new industry as illustrated by the case of regenerative medicine in Finland (Sotarauta and Heinonen 2016). In contrast, abstract economic space is the main source for path importation. It rests on technologies and routines of industries developed elsewhere. In the absence of relevant competencies regionally, this form of path development should in most cases be traceable to the involvement of external actors (firms or individuals), who may seek assets (raw materials, qualified or cheap labour, land) or access to markets (Dicken 2011).

Having substantiated how different types of new path development are rooted in concrete geographic and abstract economic space, this should not obscure the interplay of regional and global processes. Regardless whether the source for new path development can be identified in the abstract economic or concrete geographic space, regional processes are always essential 
for anchoring new industries regionally and for creating the external economies that propel economic growth. This requires developing supportive industries and services, a specialised labour force, and an institutional environment that is conducive for learning and innovation, as well as stimulating regional knowledge and input-output linkages. These factors further stimulate the entry of new firms, spin-offs and the development of a critical mass in the new industry (Mudambi and Santangelo 2015). Furthermore, even though concrete geographic space is expected to play an essential role for new path creation, this does not imply that regional actors cannot draw on extra-regional sources or that they are detached from influences at higher spatial scales. Indeed, with the emergence and growth of a new-to-theworld industry, networks and institutions at higher spatial scales will quickly gain in importance. Moreover, as a technology becomes more mature and the market grows, a new abstract space with industry-specific technologies, institutions, and networks evolves (Nelson 1995).

Another important qualification is that different sources and forms of new path development can and often will be evoked at the same time. The largest variety of sources for new path development is found in metropolitan areas, which can draw on the benefits of specialisation and urbanisation, related and unrelated variety in concrete geographic and abstract economic space. Peripheral regions with strengths in one industry are not limited to specialisation in concrete geographic space but can potentially also tap related and unrelated variety in an abstract economic space. There are many ways that lead to new industrial path development. The conceptual framework provided here helps to disentangle the causal mechanisms and the geography of new path development.

\section{Conclusions}

The paper proposes a rigorous definition of specialisation, related variety and unrelated variety removing overlaps between the three concepts. This is important in order to advance in our theoretical understanding of regional industrial dynamics. A theoretical understanding requires identifying causal mechanisms, which is made difficult if a specific term refers to different causal mechanisms, or if two terms refer to the same causal mechanism. We propose that the definition of specialisation should rest on traded and untraded interdependencies of economic activities. This is the only useful interpretation of specialisation in a knowledgebased economy whereas the concept becomes meaningless if limited to one industrial sector. 
Related variety captures the potentials for diversification resulting from similarities in the knowledge base between industries that are not interwoven with such traded and untraded interdependencies. We have shown that such industry configurations exist and are used by firms to diversify their product portfolio. Unrelated variety refers to the combination of nonsimilar knowledge.

Specialisation, related, and unrelated variety are relevant in concrete geographic (local) and abstract economic (non-local) space. This distinction unveiled some characteristics of the link between related variety and regional branching, which from our reading of the respective literature do not become very clear. First, related variety only stimulates regional branching if it exists in the non-local space. Firm diversification into related industries that already exist in the region leads to a reallocation of activities to higher-value activities; we call this shift between paths. Second, regional branching does not necessarily have to be an endogenous process but can be stimulated by investments from non-local actors active in related industries (Trippl et al. 2017).

The introduced conceptual framework captures the opportunity space for regional industrial path development in two dimensions: space (local and non-local) and structure (specialisation, related and unrelated variety). Linking this opportunity space with the typology of regional industrial path development sheds light on the importance of unrelated variety. Unrelated variety is not only the source for the most radical forms of path development (path creation and unrelated path diversification) but can also contribute to different forms of path upgrading. As such, unrelated variety appears as the most versatile source for industrial path development.

Such a conceptual framework is relevant for academics and practitioners. Going beyond the theoretical importance mentioned above, the framework provides guidance for empirical research. Quantitative research can build on the framework to sharpen measures, to target causal mechanisms, and interpret findings. The framework informs qualitative research in disentangling causes and effects. Awareness of the variegated sources and forms of regional industrial path development supports researchers in identifying the relevant relationships and reduces the risk of misinterpretations. 
The conceptual framework is useful for practitioners as it points to the various sources that can be tapped and combined to stimulate regional industrial change. Metropolitan areas have the largest opportunity space. They provide pockets of specialisations in certain industries but also related and unrelated variety. In contrast, the non-local space is, in principle, open to actors in any region. This means that a firm in a peripheral region can benefit from specialisation, related variety and unrelated variety by connecting to other actors outside the region. Having said this, regions differ in their needs for non-local sources, as well as their capacity to attract and absorb knowledge generated in other regions (Trippl et al. 2017). The conceptualisation of the opportunity space allows practitioners to reflect upon which potential for regional renewal exist in their regions and draw policy conclusions that are adequate for the respective context conditions. 


\section{References}

Asheim, B.T. 2000. Industrial districts: The contributions of Marshall and beyond. In The Oxford handbook of economic geography, ed. G.L. Clark; M.P. Feldman; and M.S. Gertler, 413-431. Oxford ; New York: Oxford University Press.

Asheim, B.T.; P. Cooke; and R. Martin. 2006. Clusters and regional development : critical reflections and explorations. New York: Routledge.

Bathelt, H.; D.F. Kogler; and A.K. Munro. 2010. A knowledge-based typology of university spin-offs in the context of regional economic development. Technovation 30:519-532.

Boschma, R. 2005. Proximity and Innovation: A Critical Assessment. Regional Studies 39:61-75.

Boschma, R. and S. Iammarino. 2009. Related Variety, Trade Linkages, and Regional Growth in Italy. Economic Geography 85:289-311.

Boschma, R.; V. Martín; and A. Minondo. 2016. Neighbour regions as the source of new industries. Papers in Regional Science 96:227-245.

Boschma, R.; A. Minondo; and M. Navarro. 2012. Related variety and regional growth in Spain*. Papers in Regional Science 91:241-256.

Chaminade, C. and J. Vang. 2008. Globalisation of knowledge production and regional innovation policy: Supporting specialized hubs in the Bangalore software industry. Research Policy 37:1684-1696.

Coe, N.M.; M. Hess; H.W.-c. Yeung; P. Dicken; and J. Henderson. 2004. 'Globalizing' regional development: a global production networks perspective. Transactions of the Institute of British Geographers 29:468-484.

Content, J. and K. Frenken. 2016. Related variety and economic development: a literature review. European Planning Studies:1-16.

Cooke, P. 2012. Global Production Networks and Global Innovation Networks: Stability Versus Growth. European Planning Studies 21:1081-1094.

Dicken, P. 2011. Global shift. Mapping the changing contours of the world economy. New York: The Guilford Press.

Ellison, J. 2017. Can wearable tech be sexy. In Financial Times (20 May 2017).

Florida, R.; P. Adler; and C. Mellander. 2017. The city as innovation machine. Regional Studies 51:86-96.

Frenken, K. and R.A. Boschma. 2007. A theoretical framework for evolutionary economic geography: industrial dynamics and urban growth as a branching process. Journal of Economic Geography 7:635-649.

Frenken, K.; F. Van Oort; and T. Verburg. 2007. Related Variety, Unrelated Variety and Regional Economic Growth. Regional Studies 41:685-697.

Grillitsch, M.; R. Martin; and M. Srholec. 2016. Knowledge Base Combinations and Innovation Performance in Swedish Regions. Economic Geography:1-22.

Grillitsch, M. and M. Trippl. 2016. Innovation Policies and New Regional Growth Paths: A place-based system failure framework. Papers in Innovation Studies.

Hassink, R. 2010. Locked in decline? On the role of regional lock-ins in old industrial areas. In The Handbook of Evolutionary Economic Geography, ed. R. Boschma and R. Martin, 450-468. Cheltenham: Edward Elgar.

Henderson, J.; P. Dicken; M. Hess; N. Coe; and H.W.-C. Yeung. 2002. Global production networks and the analysis of economic development. Review of International Political Economy 9:436-464.

Hidalgo, C.A.; B. Klinger; A.-L. Barabási; and R. Hausmann. 2007. The Product Space Conditions the Development of Nations. Science 317:482-487. 
Isaksen, A. and M. Trippl. 2016. Path Development in Different Regional Innovation Systems. In Innovation Drivers and Regional Innovation Strategies, ed. M. Parrilli; R. Fitjar; and A. Rodríguez-Pose, 66-84. New York and London: Routledge.

Isaksen, A.; F. Tödtling; and M. Trippl. 2016. Innovation policies for regional structural change: combining actor-based and system-based strategies. In 56th ERSA Congress August 23-26. Vienna, Austria.

Kemeny, T. and M. Storper. 2015. Is Specialization Good for Regional Economic Development? Regional Studies 49:1003-1018.

Klepper, S. 2007. Disagreements, Spinoffs, and the Evolution of Detroit as the Capital of the U.S. Automobile Industry. Management Science 53:616-631.

Lundvall, B.-A. 1988. Innovation as an interactive process: from user-producer interaction to the national system of innovation. In Technical change and economic theory, ed. G. Dosi; C. Freeman; R. Nelson; G. Silverberg; and L.L. Soete, 349-369. London: Frances Pinter.

MacKinnon, D. 2012. Beyond strategic coupling: reassessing the firm-region nexus in global production networks. Journal of Economic Geography 12:227-245.

Marshall, A. 1920. Principles of economics : an introductory volume. London: Macmillan.

Martin, R. and J. Simmie. 2008. Path dependence and local innovation systems in cityregions. Innovation 10:183-196.

Martin, R. and P. Sunley. 2006. Path dependence and regional economic evolution. Journal of Economic Geography 6:395-437.

Mudambi, R. and G.D. Santangelo. 2015. From Shallow Resource Pools to Emerging Clusters: The Role of Multinational Enterprise Subsidiaries in Peripheral Areas. Regional Studies:1-15.

Nam, K.-M. and X. Li. 2012. Out of passivity: potential role of OFDI in IFDI-based learning trajectory. Industrial and Corporate Change 22:711-743.

Neffke, F.; M. Hartog; R. Boschma; and M. Henning. 2014. Agents of structural change. The role of firms and entrepreneurs in regional diversification. Papers in Evolutionary Economic Geography, Uttrecht University.

Nelson, R.R. 1995. Co-evolution of Industry Structure, Technology and Supporting Institutions, and the Making of Comparative Advantage. International Journal of the Economics of Business 2:171-184.

Parrilli, M.D.; K. Nadvi; and H.W.-C. Yeung. 2013. Local and Regional Development in Global Value Chains, Production Networks and Innovation Networks: A Comparative Review and the Challenges for Future Research. European Planning Studies 21:967988.

Perroux, F. 1970. Note on the Concept of Growth Poles. In Regional Economics: Theory and Practice, ed. D. McKee; R. Dean; and W. Leahy, 93-103. New York: The Free Press.

Porter, M.E. 1990. The Competitive Advantage of Nations. London: Macmillan.

Porter, M.E. 1998. Clusters and the new economics of competition. Harvard Business Review 76:77-90.

Pouder, R. and C.H. St. John. 1996. Hot Spots and Blind Spots: Geographical Clusters of Firms and Innovation. Academy of Management Review 21:1192-1225.

Pyke, F.; G. Becattini; and W. Sengenberger. 1990. Industrial districts and inter-firm cooperation in Italy. Geneva: International Institute for Labour Studies.

Saviotti, P.P. and K. Frenken. 2008. Export variety and the economic performance of countries. Journal of Evolutionary Economics 18:201-218.

Saxenian, A. 1994. Regional advantage : culture and competition in Silicon Valley and Route 128. Cambridge, Mass.: Harvard Univ. Press.

Sotarauta, M. and T. Heinonen. 2016. The Triple Helix model and the competence set: human spare parts industry under scrutiny. Triple Helix 3:1-20. 
Storper, M. 1995. The resurgence of regional economies, ten years later: the region as a nexus of untraded interdependencies. European Urban and Regional Studies 2:191-221.

Storper, M.; T. Kemeny; N. Makarem; and T. Osman. 2015. The Rise and Fall of Urban Economies: Lessons from San Francisco and Los Angeles. Stanford: Stanford University Press.

Storper, M.; T. Kemeny; N.P. Makarem; and T. Osman. 2016. On Specialization, Divergence and Evolution: A Brief Response to Ron Martin's Review. Regional Studies 50:16281630.

Strambach, S. and B. Klement. 2013. Exploring plasticity in the development path of the automotive industry in Baden-Wurttemberg: The role of combinatorial knowledge dynamics. Zeitschrift für Wirtschaftsgeographie 57:67-82.

Tanner, A.N. 2014. Regional Branching Reconsidered: Emergence of the Fuel Cell Industry in European Regions. Economic Geography 90:403-427.

Trippl, M. 2013. Islands of Innovation as Magnetic Centres of Star Scientists? Empirical Evidence on Spatial Concentration and Mobility Patterns. Regional Studies 47:229244.

Trippl, M.; M. Grillitsch; and A. Isaksen. 2017. Exogenous sources of regional industrial change. Progress in Human Geography 0:0309132517700982.

Zukauskaite, E. and J. Moodysson. 2016. Multiple paths of development: knowledge bases and institutional characteristics of the Swedish food sector. European Planning Studies 24:589-606. 